\title{
HSP90 activity is required for MLKL oligomerisation and membrane translocation and the induction of necroptotic cell death
}

\author{
AV Jacobsen ${ }^{1,2}$, KN Lowes $^{1,2}$, MC Tanzer $^{1,2}$, IS Lucet ${ }^{1,2}$, JM Hildebrand $^{1,2}$, EJ Petrie ${ }^{1,2}$, MF van Delft ${ }^{1,2}$, Liu $^{1,2}$, SA Conos $^{1,2}$, \\ J-G Zhang ${ }^{1,2}$, DCS Huang ${ }^{1,2}$, J Silke ${ }^{1,2}$, G Lessene ${ }^{\star, 1,2,3}$ and JM Murphy ${ }^{*, 1,2}$
}

Necroptosis is a caspase-independent form of regulated cell death that has been implicated in the development of a range of inflammatory, autoimmune and neurodegenerative diseases. The pseudokinase, Mixed Lineage Kinase Domain-Like (MLKL), is the most terminal known obligatory effector in the necroptosis pathway, and is activated following phosphorylation by Receptor Interacting Protein Kinase-3 (RIPK3). Activated MLKL translocates to membranes, leading to membrane destabilisation and subsequent cell death. However, the molecular interactions governing the processes downstream of RIPK3 activation remain poorly defined. Using a phenotypic screen, we identified seven heat-shock protein 90 (HSP90) inhibitors that inhibited necroptosis in both wild-type fibroblasts and fibroblasts expressing an activated mutant of MLKL. We observed a modest reduction in MLKL protein levels in human and murine cells following HSP9O inhibition, which was only apparent after $15 \mathrm{~h}$ of treatment. The delayed reduction in MLKL protein abundance was unlikely to completely account for defective necroptosis, and, consistent with this, we also found inhibition of HSP90 blocked membrane translocation of activated MLKL. Together, these findings implicate HSP90 as a modulator of necroptosis at the level of MLKL, a function that complements HSP90's previously demonstrated modulation of the upstream necroptosis effector kinases, RIPK1 and RIPK3.

Cell Death and Disease (2016) 7, e2051; doi:10.1038/cddis.2015.386; published online 14 January 2016

Necroptosis is an inflammatory, caspase-independent form of regulated cell death characterised by loss of cellular membrane integrity and release of cytoplasmic contents. ${ }^{1}$ It is believed to have evolved as a defence mechanism against viruses; ${ }^{2,3}$ however, there is increasing evidence that deregulated necroptosis has a role in the pathogenesis of a range of inflammatory, autoimmune and neurodegenerative diseases. ${ }^{4-8}$ Reduced capacity to undergo necroptosis has been correlated to increased aggressiveness of cancers; ${ }^{9,10}$ and therapeutic initiation of necroptosis is currently being investigated as a cancer therapy. ${ }^{11,12}$ Additionally, there is emerging evidence that the necroptotic signalling pathway has a general role in the modulation of inflammation. ${ }^{13-17}$ As such, unravelling the molecular events governing necroptosis, and potential avenues for therapeutic intervention, is of enormous interest.

Necroptosis is initiated through activation of death receptors, such as Tumour Necrosis Factor Receptor 1 (TNFR1), or through microbial activation of pattern recognition receptors, such as Toll-like receptors or intracellular viral DNA sensors. ${ }^{3,18-20}$ Receptor ligation initiates a signalling cascade, whereby Receptor Interacting Protein Kinase (RIPK)-3 oligomerises and is phosphorylated, a process known to be regulated by association with other effectors, such as the protein kinase RIPK1, TIR-domain-containing adapter-inducing
IFN- $\beta$ (TRIF), or DNA-dependent activator of IFN regulatory factors (DAI), via their RIP Homotypic Interaction Motifs (RHIMs). 2,21,22 Once activated, RIPK3 phosphorylates the pseudokinase domain of Mixed Lineage Kinase domain-Like (MLKL), the most downstream known obligate effector of the necroptotic signalling pathway, to induce its activation. ${ }^{23,24}$ MLKL phosphorylation is thought to trigger a molecular switch, ${ }^{25-27}$ leading to the unleashing of the N-terminal executioner four-helix bundle (4HB) domain, ${ }^{28} \mathrm{MLKL}$ oligomerisation and translocation to cellular membranes where cell death occurs via an incompletely-understood mechanism. ${ }^{28-30}$

Molecular chaperones have an integral role in modulating both the structure and function of proteins. One such chaperone is heat-shock protein 90 (HSP90), which interacts with a diverse group of protein 'clients', the largest group comprising the kinases and pseudokinases, with $50 \%$ of the human kinome estimated to interact with HSP90. ${ }^{31}$ These interactions are dependent on the recognition of the kinase or pseudokinase domain by the HSP90 co-chaperone Cdc37, which enables HSP90 to confer protein stabilisation, assist in late-stage folding and conformational modifications, and mediate intracellular transport. ${ }^{32-35}$

It has already been demonstrated that the necroptotic pathway is subject to modulation by HSP90. RIPK1 is well

\footnotetext{
${ }^{1}$ The Walter and Eliza Hall Institute of Medical Research, Parkville, VIC, Australia; ${ }^{2}$ Department of Medical Biology, University of Melbourne, Parkville, VIC, Australia and ${ }^{3}$ Department of Pharmacology and Therapeutics, University of Melbourne, Parkville, VIC, Australia

*Corresponding author: G Lessene or JM Murphy, The Walter and Eliza Hall Institute of Medical Research, 1G Royal Parade, Parkville, VIC 3052, Australia. Tel: +61 393452878 (GL) or +61 393452407 (JMM); Fax: +61 393470852; E-mail: glessene@ @ehi.edu.au or jamesm@ @ehi.edu.au

Abbreviations: MLKL, mixed lineage kinase domain-like; 4HB, four-helix bundle; RIPK, receptor interacting protein kinase; HSP90, heat-shock protein 90; Cdc37, cell division cycle 37; TNF, tumour necrosis factor; TNFR1, tumour necrosis factor receptor 1; TSQ, TNF (T), Smac mimetic Compound A (S), and QVD-OPh (Q); PI, propidium iodide; MDF, murine dermal fibroblast; SEC, size-exclusion chromatography; DMEM, Dulbecco's modified Eagle's medium; FCS, fetal calf serum Received 10.8.15; revised 30.11.15; accepted 02.12.15; Edited by E Baehrecke
} 

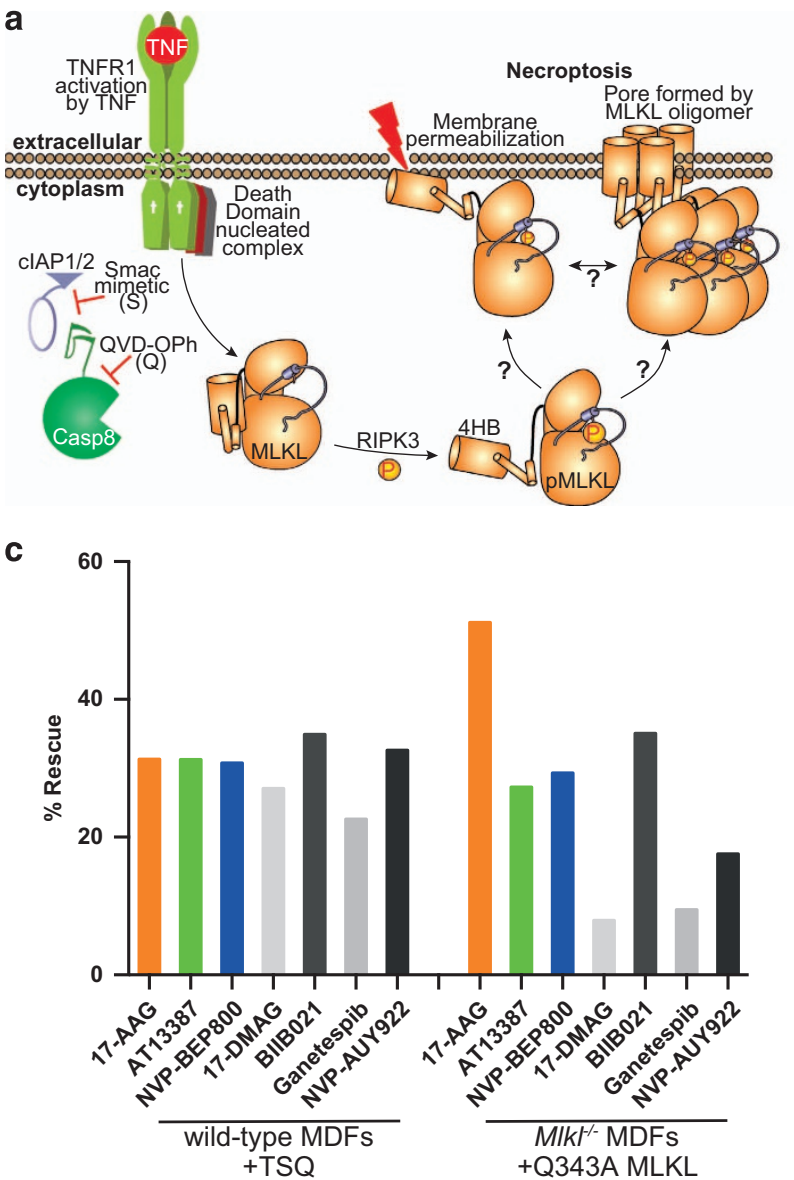

b

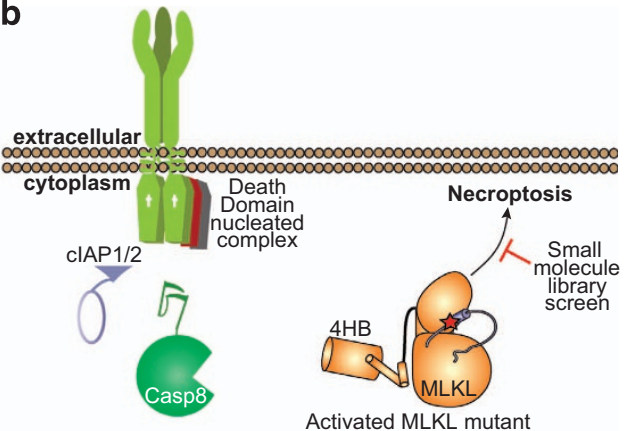

d

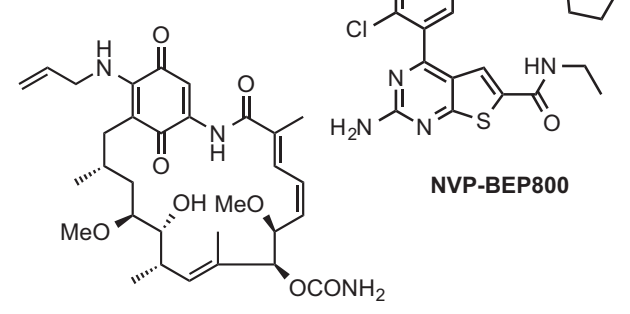<smiles>CC(C)c1cc(C(=O)N2Cc3ccc(CN4CCN(C)CC4)cc3C2)c(O)cc1O</smiles>

Figure 1 Hsp90 inhibitors can block necroptosis downstream of MLKL activation. (a) A schematic of the necroptosis pathway. TNF (T) stimulates the TNFR1; cIAP1/2 activity is blocked with Smac mimetic (S); and the pan-caspase inhibitor, QVD-OPh (Q), blocks caspase-8 activity. This leads to RIPK3 activation and subsequent phosphorylation and activation of MLKL. (b) The activated MLKL mutant Q343A initiates cell death in the absence of TSQ stimulation or RIPK3 activation enabling a screen for inhibitors of necroptosis downstream of MLKL activation. (c) Cells were pretreated for $2 \mathrm{~h}$ with a library of 438 compounds with annotated mechanisms of action at $1 \mu \mathrm{M}$, then necroptosis was stimulated in wild-type MDFs with TSQ and expression of Q343A MLKL was induced in MIk $\digamma^{\prime-}$ MDFs with doxycycline. Percentage rescue was determined using a CellTiter Glo assay, and normalised against TSQ/doxycycline stimulation and DMSO treatment. The data represent the HSP90 hits from each screen, and are the average of two technical replicates. (d) Chemical structures of the three compounds selected for further analysis

established as an HSP90 client protein, with a number of studies finding HSP90 inhibition affects both the stability and function of RIPK1 and promotes an apoptotic phenotype. ${ }^{36-41}$ More recently, RIPK3 was also identified as an HSP90 client. $^{2,42,43}$ Surprisingly, HSP90 inhibition did not markedly impact RIPK3 abundance or stability, but rather was essential for RIPK3's necroptotic functions, such as phosphorylation of MLKL. ${ }^{42}$ However, whether MLKL itself is a client of HSP90 has not been investigated.

In this study, using a phenotypic screen for small-molecule inhibitors of MLKL-driven cell death, we identified HSP90 as a modulator of necroptosis that functions on, or downstream of, the terminal effector, MLKL. HSP90 inhibition did not markedly reduce levels of MLKL in human U937 or mouse dermal fibroblasts, suggesting instead that HSP90 has an active role in governing MLKL-mediated cell death. This idea is supported by our finding that cell death driven by the S345D activated mutant of MLKL in Ripk3-deficient fibroblasts in the absence of necroptotic stimuli was suppressed by three distinct chemical classes of HSP90 inhibitor, but MLKL abundance was not impacted by HSP90 inhibition. Although our data indicate that MLKL binds HSP90 weakly or transiently, HSP90 activity was essential for the assembly of MLKL into high molecular weight complexes and the membrane translocation known to precede cell death. These findings suggest an expanded role for HSP9O in regulating necroptosis, and further our understanding of the mechanisms controlling MLKL-mediated cell death.

\section{Results}

HSP90 modulates necroptosis independent of MLKL activation. To identify small-molecule inhibitors of necroptosis, we performed phenotypic screens with a library comprising 438 small molecules with well-annotated mode of actions in both wild-type murine dermal fibroblasts (MDFs) treated with necroptotic stimuli (Figure 1a) and $\mathrm{MlkF}^{\prime-}$ MDFs inducibly expressing the Q343A activated mutant of MLKL, which undergoes cell death in the absence of stimuli 
(Figure 1b). Necroptosis was induced in wild-type MDFs using conventional necroptotic stimuli: tumour necrosis factor (TNF; T), to activate TNF receptor 1; the Smac mimetic, Compound A (S), to inhibit clAP (cellular inhibitor of apoptosis proteins)-mediated ubiquitylation of RIPK1 and permit its participation in cell death signalling; and the pan-caspase inhibitor, Q-VD-OPh (Q), to inhibit caspase-8 and permit necroptosis (Figure 1a). In parallel, the same library of 438 compounds was tested in Mlk ${ }^{\prime-}$ MDFs reconstituted with the Q343A mutant MLKL, which we previously showed to induce cell death in the absence of necroptotic stimuli, independently of RIPK3 activity (Figure 1b). ${ }^{25}$ Compounds that conferred protection against necroptotic cell death were identified by measuring cell viability using a CellTiter Glo assay.

All seven HSP90 inhibitors within our small-molecule library protected wild-type MDFs from undergoing TSQ-induced necroptosis and, strikingly, provided some protection to $\mathrm{MlkF}^{\prime-}$ MDFs undergoing stimulus-independent death driven by the Q343A MLKL mutant (Figure 1c). Approximately 30\% rescue from TSQ-driven cell death in wild-type MDFs was conferred by each of the seven HSP90 inhibitors (Figure 1c). Four of the seven inhibitors, 17-AAG, AT13387, NVP-BEP800 and BIIB021, also provided substantial protection from Q343A MLKL-mediated cell death. These four HSP90 inhibitors belong to distinct chemical classes, ruling out any off-target effects of these small molecules on the necroptotic pathway. These results, therefore, implicate HSP90 as a modulator of the necroptosis pathway downstream of MLKL activation.

We selected the most potent inhibitor, the geldanamycin analogue 17-AAG, along with two other inhibitors from distinct chemical classes; AT13387 and NVP-BEP800 (Figure 1d), to further explore the role of HSP90 in necroptosis. We selected compounds from three distinct chemical classes to eliminate the possibility that their inhibition of necroptosis occurs via offtarget effects. Because these compounds all inhibit HSP90 through engagement of the ATP binding site, ${ }^{44-46}$ we performed a thermal shift assay to assess whether the antinecroptotic function of HSP90 inhibitors might arise from offtarget binding to the MLKL ATP binding pocket. However, none of these three compounds induced a marked thermal shift of either the mouse or human MLKL pseudokinase domains, or full-length mouse or human MLKL. This suggests that HSP90 inhibitors do not act directly on MLKL (Supplementary Figure 1 ), but rather function via inhibition of HSP90 activity.

HSP90 inhibition subtly reduced endogenous MLKL protein levels. We performed titrations of 17-AAG, AT13387 and NVP-BEP800 on wild-type MDFs and U937, a human histiocytic lymphoma cell line, to determine the optimal concentrations for further analysis (Supplementary Figure 2). Cells were pretreated for $1 \mathrm{~h}$ with each inhibitor before induction of necroptosis by addition of TSQ, and cell death quantified by propidium iodide uptake after $24 \mathrm{~h}$ by flow cytometry. All three HSP90 inhibitors provided approximately 20-30\% protection from TSQ-mediated killing in MDFs, which was consistent with the results of our primary phenotypic screen (Figure 2a). In U937, pre-treatment with inhibitors was less intrinsically toxic at higher concentrations of inhibitors than in MDFs and resulted in near complete protection (Figure $2 b$ ).
A common function of HSP90 is to protect client proteins from degradation. Upon loss of HSP90 protection, client proteins revert to a partially folded state, making them more likely to aggregate and undergo proteasomal degradation. ${ }^{39,47}$ As such, a decrease in protein level in response to HSP90 inhibition is suggestive of HSP90 client status. We examined the effects of HSP90 inhibition in wild-type and Ripk3 ${ }^{-1}$ MDFs and found there was indeed a decrease in MLKL protein levels, which was subtle but became most apparent after 15-24 h of treatment (Figures $2 \mathrm{c}$ and $\mathrm{d}$ ). This was accompanied by $\mathrm{a}$ decrease in protein levels of other known clients in the necroptosis pathway, RIPK1 and RIPK3. RIPK1 levels were also noticeably reduced in U937 cells following HSP90 inhibition (Figure $2 \mathrm{e}$ ). These results suggest that MLKL stability is not dramatically affected by HSP90 inhibition. We therefore sought other explanations for loss of MLKL killing activity.

HSP90 is required for MLKL protein function. We have proposed that the auto-activating MLKL Q343A mutant is in an activated conformation that exposes the $\mathrm{N}$-terminal executioner four-helix bundle (4HB) domain thereby leading to cell death. ${ }^{25}$ Consistent with this proposal, expression of the $4 \mathrm{HB}$ domain of MLKL is sufficient to kill cells. ${ }^{28}$ We therefore hypothesised that HSP90 might directly regulate the killing activity of $4 \mathrm{HB}$ domain. To test this, we inducibly expressed a truncated MLKL construct encoding residues 1-180, which incorporates the executioner 4HB domain, in wild-type MDFs pretreated with our panel of HSP90 inhibitors. However, HSP90 inhibition did not prevent 4HB domain-induced death (Figure 3a). The amount of cell death was also unaffected when the MLKL(1-180) construct was expressed in either $\mathrm{MlkF}^{-1-}$ or Ripk3 ${ }^{-1}$ MDFs (Figures $3 \mathrm{~b}$ and c). These data suggest that HSP90 acts at the level of MLKL activation, probably via a mechanism that depends on the presence of the C-terminal pseudokinase domain of MLKL.

To explore this hypothesis, we used a previously-described MLKL S345D mutant that mimics RIPK3-mediated activation loop phosphorylation and thereby causes stimulus-independent activation of MLKL. ${ }^{25}$ To completely eliminate any possible contribution of RIPK3, this protein was inducibly expressed in Ripk ${ }^{-1-} \mathrm{Mlk}^{\prime-}$ double knockout (DKO) MDFs. In contrast to the cell death induced by the $4 \mathrm{HB}$ domain alone, but consistent with our original screen, all three inhibitors showed substantial protection from S345D MLKL-mediated killing (Figure 3d).

Although this result suggested that HSP90 was involved in the conversion of MLKL into its activated form downstream of RIPK3, mutated proteins have been shown to have a greater reliance on HSP90 for stabilisation. ${ }^{48,49}$ To evaluate whether reduced stability of the S345D MLKL mutant following HSP90 inhibition might explain the striking reduction in necroptosis, we evaluated levels of this mutant over a 24-h time period. Interestingly, S345D levels were not notably reduced by any HSP90 inhibitor (Figure 3e). We also evaluated the effect of HSP90 inhibition on the levels of inducibly-expressed wildtype MLKL in $\mathrm{MlkI}^{\prime-}$ MDFs, and found protein levels to be comparable to those observed in $\mathrm{MlkI}^{\prime-}$ MDFs expressing the S345D MLKL mutant (Figure 3f). Together, these data indicate that HSP90 has a role in converting MLKL into its activated form, rather than in regulating its abundance. 
HSP90 activity is necessary for MLKL oligomerisation and translocation to the membrane. A critical step in MLKL-induced killing entails membrane translocation, and
HSP90 has been shown to regulate trafficking of proteins to the plasma membrane. ${ }^{32,50}$ We therefore asked whether HSP90 might have an important role in mediating MLKL a

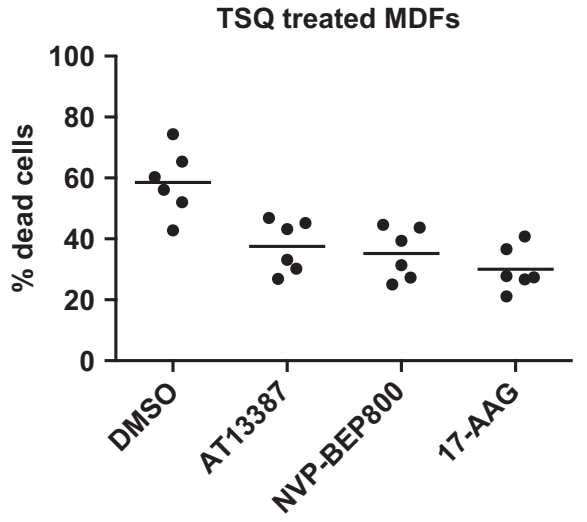

b

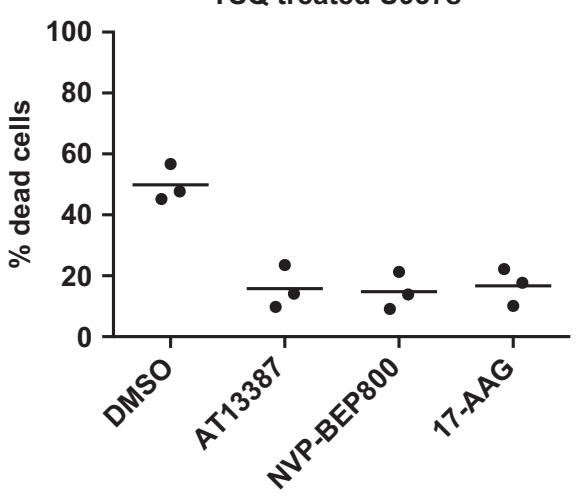

C

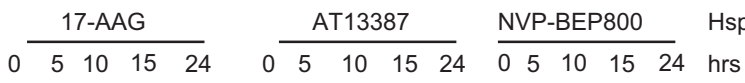

WB: anti-MLKL

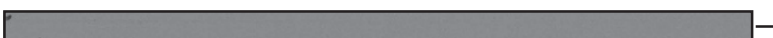

$66.2 \mathrm{kDa}$

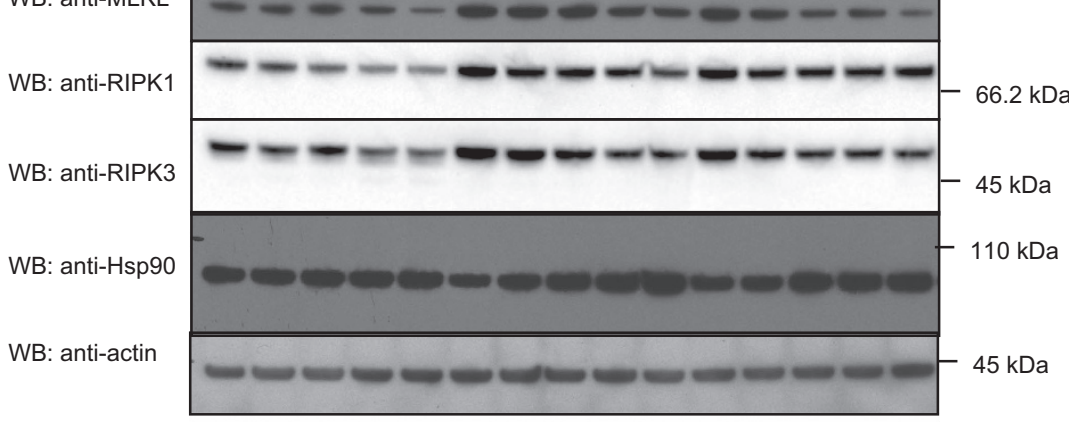

d

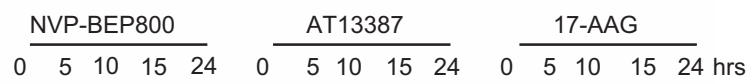

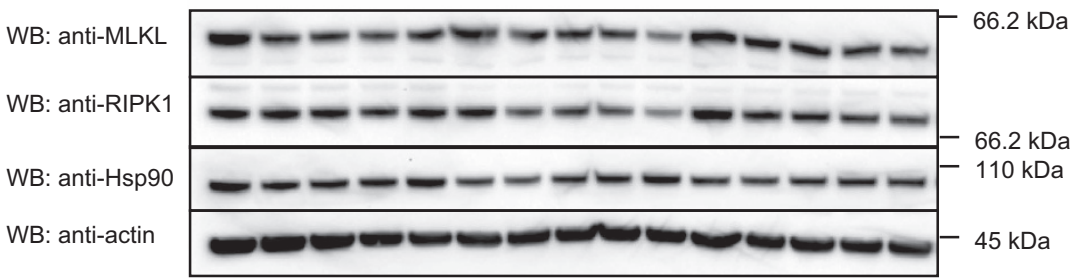

Wild-type MDFs

Ripk3\% $^{-1}$

MDFs

e

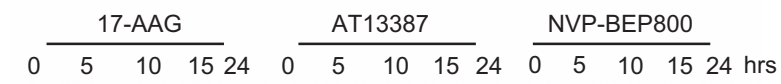

WB: anti-MLKL

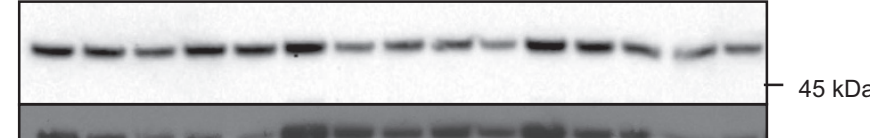

WB: anti-RIPK1

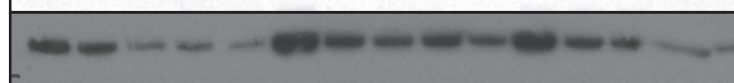

WB: anti-RIPK3

WB: anti-Hsp90

WB: anti-actin

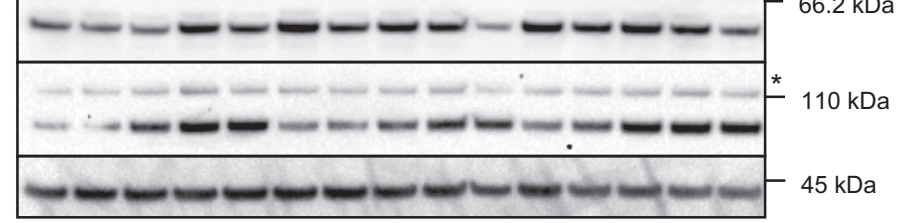


translocation to the membrane fraction. To investigate this possibility, we treated Ripk3 ${ }^{\prime-} \mathrm{MlkF}^{\prime-}$ double knockout MDFs expressing S345D MLKL with either DMSO or HSP90 inhibitors for $7 \mathrm{~h}$ and performed Blue Native PAGE on the cytoplasmic and membrane fractions (Figure $4 \mathrm{a}$ ). Consistent with the HSP90 inhibitors' ability to protect from necroptosis, they greatly reduced the amount of S345D MLKL present in the membrane fraction and prevented the formation of the high molecular weight complexes that we have previously described as a hallmark of necroptotic cell death. ${ }^{28,51}$ Because HSP90 has been established as a regulator of RIPK1, ${ }^{36-41}$ RIPK3, ${ }^{2,42,43}$ and now MLKL (herein), it was unsurprising that treatment of TSQ-stimulated U937 cells with the HSP90 inhibitors, 17-AAG or NVP-BEP800, similarly inhibited the assembly of endogenous MLKL into high molecular weight species and membrane translocation, as assessed by Blue Native PAGE (Supplementary Figure 3a).

Although we found that the membrane translocation of the S345D activated MLKL mutant was blocked by HSP90 inhibitors, it remained of interest whether HSP90 may also contribute to the assembly of MLKL oligomers. To further examine this possibility, we used a construct in which fulllength wild-type mouse MLKL was C-terminally fused to the E. coli DNA GyraseB domain, which can be dimerised by treatment with the divalent antibiotic, coumermycin. ${ }^{52,53}$ As described elsewhere, doxycycline-induced expression of MLKL-gyrase in wild-type or $\mathrm{MlkF}^{\prime-}$ MDFs did not induce cell death unless MLKL-gyrase was dimerised by the addition of coumermycin (Figures $4 \mathrm{~b}$ and $\mathrm{c}$ ). ${ }^{53}$ The extent of cell death induced by forced dimerisation of MLKL-gyrase was impaired, but still measurable, in the presence of HSP90 inhibitors (Figures $4 b$ and $c$ ). These data suggest that HSP90 may function in the assembly of higher order complexes, either by promoting an MLKL conformation that can assemble into oligomers or by recruitment of auxiliary proteins, following MLKL activation by RIPK3. It is possible, however, that HSP90 may also contribute to downstream necroptosis effects, such as mediating or promoting MLKL membrane translocation.

MLKL interacts transiently with HSP90 via the co-chaperone, Cdc37. The finding that HSP90 activity on MLKL relied on the presence of the MLKL pseudokinase domain (Figures $3 a-d)$ led us to test whether the kinase/ pseudokinase co-chaperone, Cdc37, might serve as an adaptor for HSP90 recruitment. We used siRNA to knockdown Cdc37 expression in $\mathrm{Mlk}^{\prime-}$ Ripk3 $^{-1}$ MDFs expressing the S345D activated MLKL mutant (Figure 5a), which led to a corresponding reduction in S345D MLKL-mediated cell death (Figure $5 \mathrm{~b}$ ).
Although these data indicate that Cdc37 serves as a co-chaperone to bridge HSP90 and MLKL, it remained of interest to better understand the nature of the interaction between MLKL and HSP90. To this end, using a S345D MLKL construct bearing a C-terminal Strepll tag, we attempted to co-immunoprecipitate HSP90 from MDF cell lysates. Unexpectedly, we did not observe a robust interaction between S345D mouse MLKL-Strepll and HSP90 in StrepTactin pulldown experiments (Supplementary Figure $3 \mathrm{~b}$ ), leading us to speculate that the MLKL/HSP90 interaction may be weak or transient. As a result, we sought to assess whether an interaction could be detected between endogenous MLKL and HSP90 under non-necroptotic conditions. We reasoned that interpreting whether MLKL binds HSP90 under necroptotic conditions was potentially confounded by earlier reports that MLKL is recruited to the necrosome, ${ }^{23,24}$ a complex containing RIPK1 and RIPK3, which themselves are known HSP90 interactors. We further reasoned that owing to the decrease in endogenous protein observed in unstimulated cells treated with HSP90 inhibitors (Figure 2), MLKL may interact with HSP90 before induction of necroptosis, analogous to reported observations for RIPK1 and RIPK3. ${ }^{42}$ To address this, we subjected lysates from U937 cells treated with DMSO (Figure 5c) or 17-AAG (Figure 5d) to Superose-6 sizeexclusion chromatography fractionation and used western blot analyses to determine whether HSP90 and MLKL coelute. The elution profiles indicated that HSP90 and MLKL elute as separate, but overlapping, peaks. The almost identical profiles observed in control (DMSO; Figure 5c) and 17-AAGtreated (Figure $5 d$ ) lysate fractionations confirmed that HSP90 activity had no bearing on the elution profile of MLKL. Collectively, these data suggest that the effect of HSP90 on MLKL is mediated via a weak or transient, rather than stable, interaction.

\section{Discussion}

Although active kinases are well established as HSP90 clients, the impact of this chaperone on pseudokinase stability and function is less well described. Several pseudokinases, including PSKH2, NPR2/ANP $\beta$, EphB6, KSR1, KSR2 and ErbB3/HER3, were implicated as HSP90 clients in a study of a large portion of the human kinome. ${ }^{31}$ However, the impact of HSP90 on pseudokinase function has only been described for a handful of these intriguing proteins. Ryk, EphB6 and integrin linked kinase (ILK) have been shown to be stabilised through interaction with HSP90, ${ }^{33,54-56}$ while ErbB3/HER3 maturation and cell-surface translocation were found to rely on HSP9O activity. ${ }^{57}$ In this study, we show that necroptosis induction by the pseudokinase MLKL is regulated by HSP90 activity.

Figure 2 MLKL levels are modestly reduced by Hsp90 inhibition. (a) MDFs were pretreated for $1 \mathrm{~h}$ with AT13387 (1 $\mu$ M), NVP-BEP800 (125 nM), $17-A A G(250 \mathrm{nM})$ or DMSO, then necroptosis was induced with TSQ. After $24 \mathrm{~h}$, propidium iodide $(\mathrm{PI})$ uptake was measured using flow cytometry. Each data point represents results from one of three independent cell lines tested in two experiments and solid bar indicates average $(n=6)$. (b) U937 cells were pretreated for $1 \mathrm{~h}$ with AT13387 $(2 \mu \mathrm{M})$, NVP-BEP800 $(1 \mu \mathrm{M})$, 17-AAG ( $500 \mathrm{nM}$ ) or DMSO, then necroptosis was induced with TSQ. After $24 \mathrm{~h}$, Pl uptake was measured using flow cytometry. Each data point represents results from the U937 cell line tested in three independent experiments and solid bar indicates average $(n=3)$. (c and d) Wild-type (c) or Ripk $3^{-1}$ (d) MDFs were treated with AT13387 (1 $\left.\mu \mathrm{M}\right)$, NVP-BEP800 (125 nM) or 17-AAG (250 nM) for the indicated times, then cell lysates analysed with western blotting using the indicated antibodies. Data are representative of three independent experiments. (e) U937 cells were treated with AT13387 $(2 \mu \mathrm{M})$, NVP-BEP800 (1 $\mu \mathrm{M})$ or 17-AAG (500 nM) over a 24-h time course, then cell lysates analysed with western blotting using the indicated antibodies. Data are representative of three independent experiments. *Represents non-specific band at $\sim 110 \mathrm{kDa}$ 
HSP90 frequently stabilises its client proteins and in its absence, or when it is inhibited, client proteins are more rapidly turned over by the ubiquitylation/proteasomal machinery. ${ }^{58}$ Although we observed a modest reduction in protein levels of endogenous MLKL in response to three different HSP90 inhibitors, this was not as dramatic as the reduction in levels of a well-known HSP90 client, RIPK1, in the same cells. Furthermore, when MLKL was ectopically expressed, HSP90 a

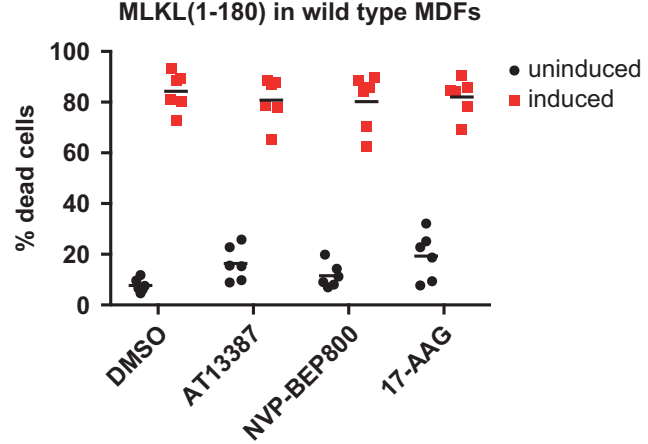

C

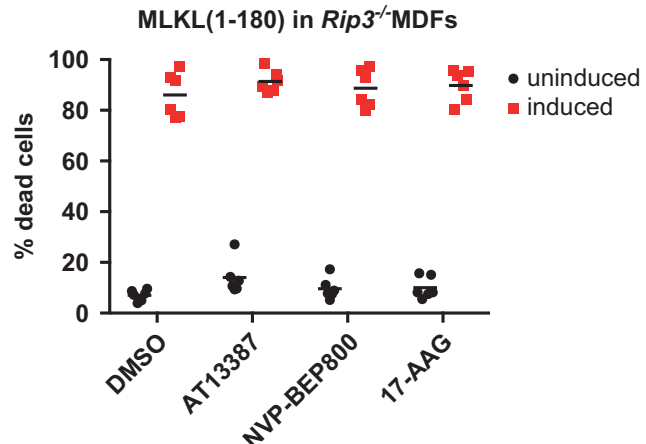

b

MLKL(1-180) in $M I k r^{-/}$MDFs

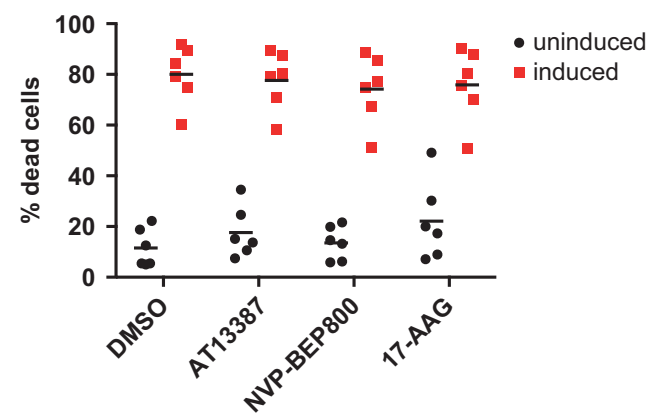

d MLKL S345D in $\mathrm{MIkr}^{/-}$Ripk $^{-/-}$MDFs

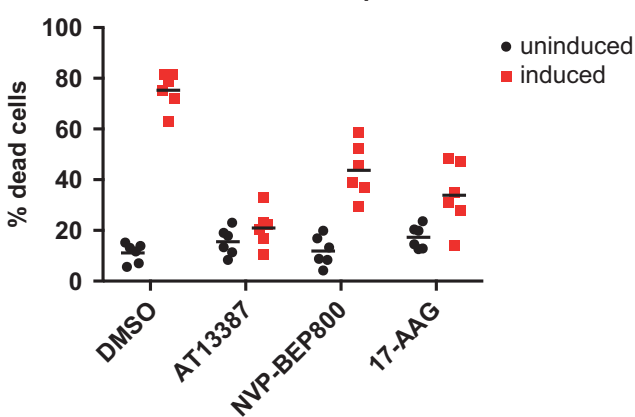

e

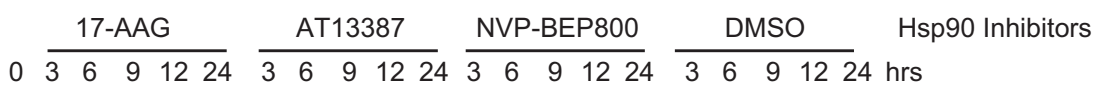

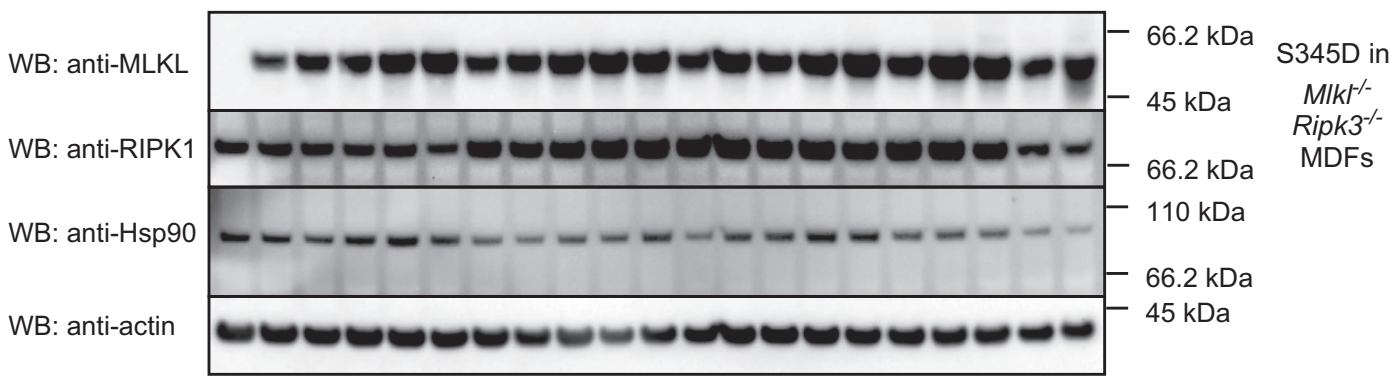

f

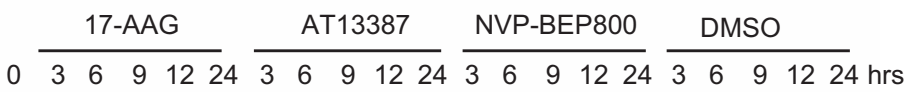

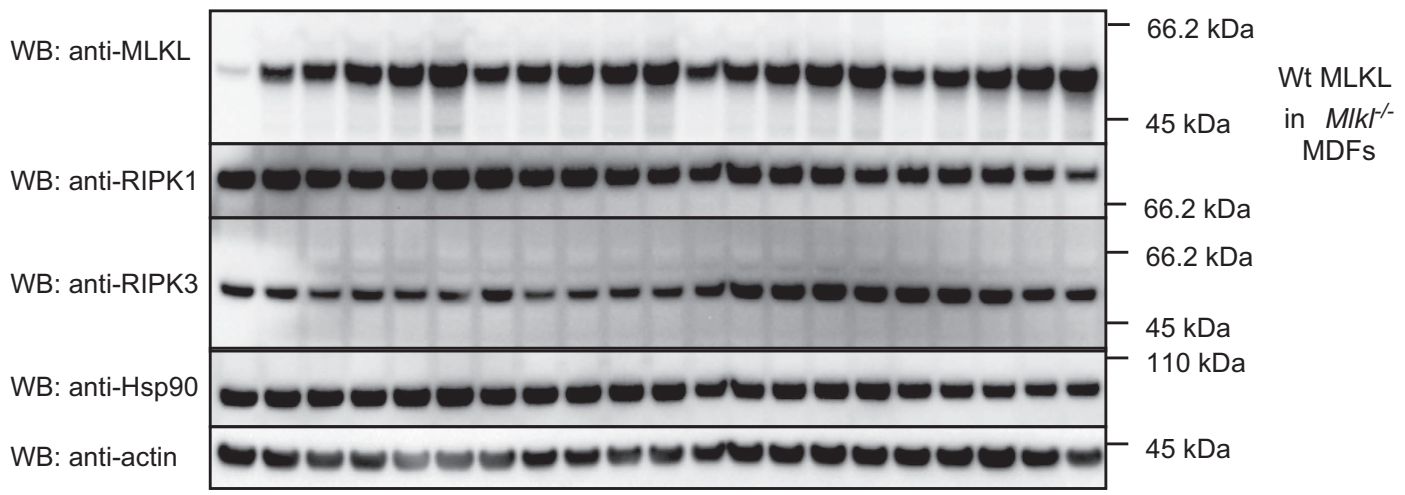


inhibition had no discernible effect on its levels. Based on our observations that HSP90 interaction with MLKL is likely to be weak or transitory, rather than stable, it would be surprising if HSP90 markedly contributed to the maintenance of MLKL protein levels. This transient interaction is reminiscent of that between HSP90 and another TNF signalling effector, the $I_{\kappa} \mathrm{B}$ kinase holocomplex, ${ }^{59}$ which like the HSP90/MLKL interaction examined in the present work, similarly relied on the cochaperone Cdc37.

It is widely accepted that MLKL must oligomerise and translocate to membranes in order to kill cells. ${ }^{28-30,60,61}$ In mouse cells, RIPK3 phosphorylates S345 in the 'activation loop' of MLKL's pseudokinase domain and we have proposed that this phosphorylation event causes a conformational change that leads to exposure of the $\mathrm{N}$-terminal $4 \mathrm{HB}$ domain, which allows it to translocate to, and permeabilise, membranes. ${ }^{25,28}$ However, the mechanism for MLKL translocation and membrane permeabilisation is currently unclear. Consistent with a model in which RIPK3-mediated phosphorylation of MLKL S345 induces exposure of the executioner $4 \mathrm{HB}$ domain, expression of the phosphomimetic S345D MLKL mutant induces MLKL incorporation into high molecular weight membrane complexes, membrane localisation and stimulusindependent cell death, ${ }^{51}$ while expression of the $4 \mathrm{HB}$ domain alone likewise promotes necroptosis. ${ }^{28}$ HSP90 inhibitors prevented S345D MLKL-induced necroptosis, but did not prevent $4 \mathrm{HB}$ domain-induced death. These results suggest that HSP90 function is required before MLKL-mediated membrane permeabilisation: in promoting a conformation change necessary for MLKL activation, assembly of MLKL into high molecular weight complexes and/or translocation to membranes. Because HSP90 has been shown to contribute to dimerisation and activation of conventional protein kinases, such as LIM Kinase $1,{ }^{62}$ we examined whether HSP90 inhibitors blocked the cell death arising from forced dimerisation of MLKL. Cell death induced by MLKL forced dimerisation was partially blocked by HSP90 inhibitors, indicating that HSP90 serves additional functions beyond mediating MLKL dimerisation, possibly by promoting transition to an active conformation, assembly of MLKL into higher order oligomers or complexes with other protein effectors.

These findings add an additional layer of regulation to our original model for MLKL activation. Building on our earlier findings, ${ }^{25,26,28}$ we hypothesise that HSP90 is required to effect the phosphorylation-induced conformational change in MLKL, to promote MLKL assembly into higher order complexes or to direct the activated MLKL to the membrane. Notably, in the current study, the stimulus-independent death mediated by the S345D MLKL mutant circumvented the requirement for upstream signals from RIPK1 and RIPK3, allowing us to directly implicate HSP90 as a regulator of MLKL activity. Each of these possibilities is supported by the literature, because HSP90 has been shown to promote conformational modifications, ${ }^{63-65}$ facilitating protein complex formation, ${ }^{32,66,67}$ and participating in intracellular trafficking ${ }^{32,50,68}$ of conventional kinases. Indeed, within the necroptosis pathway, HSP90 was recently reported to facilitate the interaction of RIPK3 with RIPK1 and RIPK3-mediated phosphorylation of MLKL. ${ }^{42}$

It is notable that the three proteins that directly contribute to necroptosis should be regulated by HSP90. RIPK1 was first identified in 2000 as an HSP90 client ${ }^{39}$ and, as has been shown in many reports, RIPK1 is rapidly degraded upon HSP90 inhibition. ${ }^{36-38,41}$ RIPK3 was more recently shown to be an HSP90 client. 2,31,42,43,69 In our hands, with three different inhibitors, loss of RIPK1 was more pronounced in U937 cells than in MDFs. Notably, RIPK1 levels are not always affected by HSP90 inhibition as shown in a recent study where it was proposed that activation of RIPK3 is regulated by HSP90. ${ }^{42}$ Ultimately, these studies illustrate that the effects of HSP90 inhibitors on RIPK1 and RIPK3 abundance, or necroptotic signalling, vary depending on the cell line examined. Here, we showed that HSP90 inhibitors rescued $\sim 30 \%$ of mouse fibroblasts from death following exposure to a necroptotic stimulus. In contrast, mouse L929 cells exhibited $\sim 60 \%$ protection from necroptotic death following treatment with HSP90 inhibitors, ${ }^{43,69}$ whereas mouse macrophages were not protected by treatment with 17DMAG. ${ }^{42}$ Relatedly, we observed that HSP90 inhibitors were intrinsically more toxic to MDFs than U937 cells in our study, which impacted the relative protection from necroptotic death conferred by inhibiting HSP90.

Downstream of RIPK1 and RIPK3, we implicated MLKL as a direct target of HSP90, supported by the finding that killing by the auto-activating S345D mutant in Ripk3 ${ }^{-1-} \mathrm{MlkF}^{-1}$ cells was strongly inhibited by three different HSP90 inhibitors. Although HSP90 inhibitors are effective killers of tumour cells and several are well advanced in clinical trials, ${ }^{70}$ the finding that they are also efficient cell death inhibitors is less surprising now that we have a greater understanding of their effects on levels and function of three effectors in the necroptosis pathway. Furthermore, it is tempting to speculate that necroptosis inhibition could have been involved in earlier cases where HSP90 inhibitors prevented cell death. ${ }^{71}$

Taken together, our data demonstrate an expanded role for HSP90 chaperone function in necroptotic signalling. Our observations that HSP90 inhibition prevented oligomerisation and/or membrane translocation of activated MLKL, but had no bearing on cell death induced by the isolated executioner domain encoded by the MLKL(1-180) construct, suggest that HSP90 may be involved in mediating or transmitting phosphorylation-induced conformational changes in the MLKL pseudokinase domain to facilitate higher order complex

\footnotetext{
Figure $3 \mathrm{Hsp90}$ inhibition affects MLKL activity. (a-c) Wild-type (a), Mlk $\digamma^{-1}$ (b) or Ripk3 ${ }^{-1-}$ (c) MDFs were pretreated for $1 \mathrm{~h}$ with AT13387 (1 $\left.\mu \mathrm{M}\right)$, NVP-BEP800 (125 nM), 17-AAG $(250 \mathrm{nM})$ or DMSO, then expression of MLKL(1-180) was induced using $50 \mathrm{ng} / \mathrm{ml}$ doxycycline. After $24 \mathrm{~h}$, PI uptake was measured using flow cytometry. Two experiments were performed using three independent cell lines $(n=6)$. (d) $M / \mathrm{K}^{\prime-}-$ Ripk $3^{-1}$ MDFs were pretreated with HSP90 inhibitors as described above, then expression of MLKL S345D was induced using $50 \mathrm{ng} / \mathrm{ml}$ doxycycline. After $24 \mathrm{~h}$, PI uptake was measured using flow cytometry. Two experiments were performed using three independent cell lines $(n=6)$. (e and f) Cells were pretreated for $1 \mathrm{~h}$ with AT13387 $(1 \mu \mathrm{M})$, NVP-BEP800 (125 nM), 17-AAG (250 nM) or DMSO, then expression of MLKL S345D in

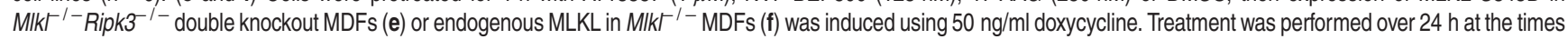
shown, then cell lysates analysed with western blotting using the indicated antibodies. Data are representative of three independent experiments
} 
a MIkt- MDFs Mlkt-- Ripk3-- MDFs $+w t$ MLKL + MLKL S345D
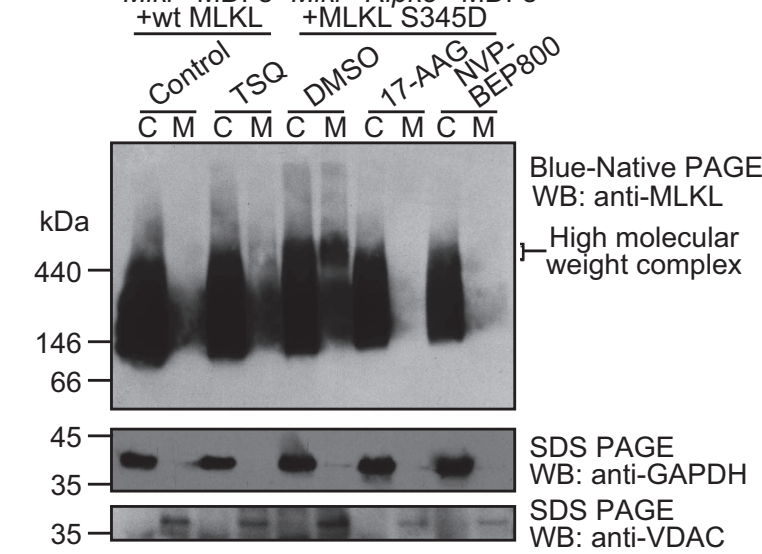

b MLKL-gyrase in wild-type MDFs
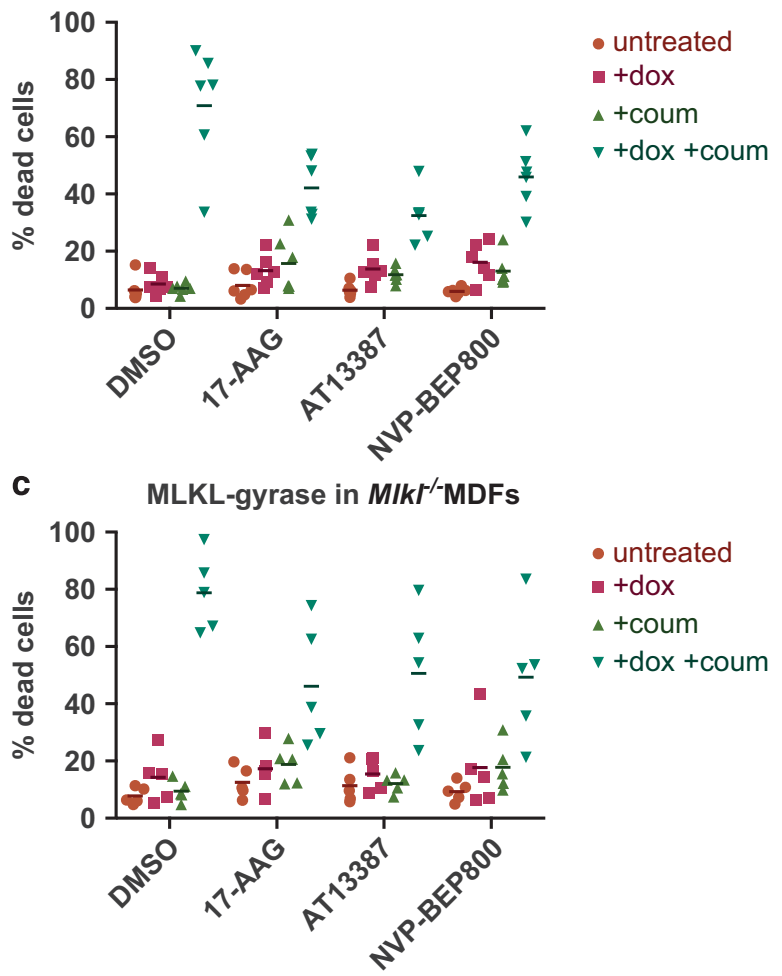

Figure 4 HSP9O is required for oligomerisation and membrane translocation of MLKL. (a) $\mathrm{MIKI}^{-1-}$ Ripk3 ${ }^{-1-}$ MDFs were pretreated for $1 \mathrm{~h}$ with NVP-BEP800 (125 nM), 17-AAG (250 nM) or DMSO then expression of MLKL S345D was induced using $50 \mathrm{ng} / \mathrm{ml}$ doxycycline. Cells were harvested when $\sim 40 \%$ of DMSO-treated cells were dead ( $7 \mathrm{~h}$ after induction). Expression of wild-type MLKL in MIK/ ${ }^{\prime-}$ MDFs was induced using $50 \mathrm{ng} / \mathrm{ml}$ doxycycline for $3 \mathrm{~h}$, then cells were either left untreated (Control) or treated with TSQ to induce necroptosis. Cells were harvested when cell death was $\sim 40 \%$ in TSQ-treated cells ( $5 \mathrm{~h}$ after TSQ treatment). Cell lysates were then separated into cytoplasmic (C) or membrane (M) fractions, and separated using Blue Native PAGE. Levels of MLKL were analysed using western blotting. Data are representative of three independent experiments using two biologically independent cell lines. (b and $\mathbf{c}$ ) Expression of wild-type full-length MLKL fused via its C-terminus to DNA gyraseB was expressed in wild-type (b) or $\mathrm{Mlk}^{\prime-}$ (c) MDFs using $50 \mathrm{ng} / \mathrm{ml}$ doxycycline (+dox) and were dimerised via treatment with $700 \mathrm{nM}$ coumermycin (+coum). Cells were pretreated for $1 \mathrm{~h}$ with AT13387 $(1 \mu \mathrm{M})$, NVP-BEP800 (125 nM), 17-AAG (250 nM) or DMSO, before MLKL-gyrase expression was induced with dox. After $24 \mathrm{~h}$, propidium iodide (PI) uptake was measured using flow cytometry. Each data point represents results from one of three independent cell lines tested in two experiments, and solid bar indicates mean ( $n=6$ for wild-type MDFs; $n=5$ for $\mathrm{Mlk}^{1-} \mathrm{MDFs}$ ) assembly and/or membrane translocation before necroptotic cell death. These results enhance our understanding of the cellular processes that underlie MLKL regulation and expand the repertoire of functions performed by HSP90 on pseudokinase clients.

\section{Materials and Methods}

Expression constructs. CDNAs encoding mouse MLKL(1-180), wild-type, Q343A or S345D mouse MLKL(1-464) were ligated into the doxycycline-inducible, puromycin-selectable vector, pF TRE3G PGK puro, as described previously. ${ }^{25,28}$ A cDNA encoding wild-type mouse MLKL(1-464) lacking a stop codon was ligated in-frame upstream of the DNA gyraseB domain within a modified version of $\mathrm{pF}$ TRE3G PGK puro, as described elsewhere. ${ }^{53}$ All insert sequences were verified by sequencing (Micromon DNA Sequencing Facility, VIC, Australia). These constructs were used to generate lentiviral particles by co-transfection of HEK293T cells with vector DNA and pVSVg and pCMV $\Delta$ R8.2 helper plasmids as before..$^{25,28}$

Antibodies, reagents and chemicals. The following primary antibodies were used for western blots of both mouse and human cell lines: anti-MLKL (produced in-house, ${ }^{25}$ available as MABC604, EMD Millipore, Billerica, MA, USA), anti-GAPDH (2118, Cell Signalling Technology, Danvers, MA, USA), anti-Actin (A-1987, Sigma-Aldrich, St Louis, MO, USA), anti-RIPK1 (610458, BD Biosciences, Franklin, NJ, USA), anti-Hsp90 (ADI-SPA-835, Enzo, Life Sciences, Farmingdale, NY, USA), anti-Cdc37 (D11A3, Cell Signalling Technology), and anti-VDAC (Sigma-Aldrich). Anti-mouse RIPK3 (PSC-2283-c100, Axxora, San Diego, CA, USA) and anti-human RIPK3 (ab56164, Abcam, Cambridge, UK) were used for their respective cell lines.

Recombinant hTNF-Fc, produced in-house, and the Smac mimetic, Compound A, were described previously. ${ }^{71,72}$ QVD-OPh was obtained from R\&D Systems (Minneapolis, MN, USA). Both NVP-BEP800 and 17-AAG were obtained from Selleckchem (Sydney, NSW, Australia), and AT13387 was produced by Active Biochem (Wanchai, Hong Kong).

Phenotypic screen. Wild-type MDFs and $M \mid \mathrm{k}^{-1-}$ MDFs expressing Q343A mutant MLKL were assessed against a small-molecule library of 438 compounds consisting of 276 kinase inhibitors, 73 targeted agents and 89 epigenetic modulators. Assay-ready 384-well white tissue culture-treated plates (Greiner Bio-One, Kremsmünster, Austria) were prepared at Compounds Australia (Nathan, QLD, Australia) by transferring compound stocks or DMSO using an ECHO liquid handler (Labcyte, Sunnyvale, CA, USA). Cells were seeded into the plates at 2000 cells/well and pre-incubated with $1 \mu \mathrm{M}$ of inhibitor for $2 \mathrm{~h}$ before addition of either doxycycline $(1 \mu \mathrm{g} / \mathrm{ml})$ or TNF $(100 \mathrm{ng} / \mathrm{ml})$, Smac mimetic $(0.5 \mu \mathrm{M})$ and QVD-OPh $(5 \mu \mathrm{M})$. After $24 \mathrm{~h}$, cell viability was determined using CellTiter Glo (Promega, Madison, WI, USA) according to the manufacturer's instructions. Assays were performed in duplicate, and data were normalised to doxycycline-/TSQ-treated controls ( $0 \%$ viability) and DMSO-treated controls ( $100 \%$ viability) and expressed as percent rescue/viability. $Z^{\prime}$ value (a measure of assay robustness) was $>0.5$ for all plates.

Cell culture and cell death assays. U937 cells were maintained in human tonicity RPMI medium supplemented with $8-10 \% \mathrm{v} / \mathrm{v}$ fetal calf serum (FCS), as before. ${ }^{51}$ Experiments were carried out in 24 -well plates, seeded at $1 \times 10^{5}$ cells per well. For cell death assays, cells were pre-incubated with 17-AAG (500 nM), AT13387 $(2 \mu \mathrm{M})$, NVP-BEP800 $(1 \mu \mathrm{M})$ or DMSO for $1 \mathrm{~h}$, then treated with TNF (100 ng/ml), Smac mimetic $(500 \mathrm{nM})$ and QVD-OPh $(10 \mu \mathrm{M})$. After $24 \mathrm{~h}$, cells were harvested, stained with propidium iodide (PI; $1 \mu \mathrm{g} / \mathrm{ml}$ ) and quantified using a FACSCalibur flow cytometer (BD Biosciences).

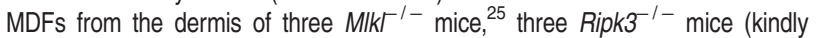

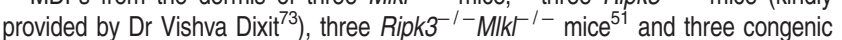
wild-type mice were isolated and immortalised to generate three biologically independent cell lines, as previously described. ${ }^{25,28}$ MDFs were cultured in Dulbecco's modified Eagle's medium (DMEM) supplemented with 8-10\% v/v FCS, with puromycin $(2 \mu \mathrm{g} / \mathrm{ml})$ included for lines stably transduced with MLKL expression constructs. Cell death assays were carried out in 24-well plates, seeded at $5 \times 10^{4}$ cells per well and allowed to attach overnight. MDFs were pre-incubated with 17-AAG (500 nM), AT13387 $(2 \mu \mathrm{M})$, NVP-BEP800 $(1 \mu \mathrm{M})$ or DMSO for $1 \mathrm{~h}$, then treated with TNF, Smac mimetic and QVD-OPh, as described above for U937 cells. After $24 \mathrm{~h}$, cells were harvested and quantified using flow cytometry as outlined above. 
Inhibitor assays and western blot. U937 cells, wild-type MDFs and Ripk $3^{-1}$ MDFs were treated with Hsp90 inhibitors as described above at indicated

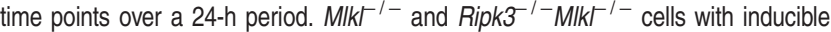
MLKL expression constructs were also treated with doxycycline $(50 \mathrm{ng} / \mathrm{ml}) 1 \mathrm{~h}$ after inhibitor treatment. Cells were harvested in RIPA lysis buffer in the presence of protease inhibitors, and total protein quantified using the bicinchoninic acid (BCA) microplate assay (ThermoScientific, Waltham, MA, USA) as per manufacturer's instructions. An equal amount of protein from each lysate was separated using SDS-PAGE and transferred onto PVDF membranes. These were incubated with primary antibodies as indicated above, HRP-conjugated secondary antibodies, and a

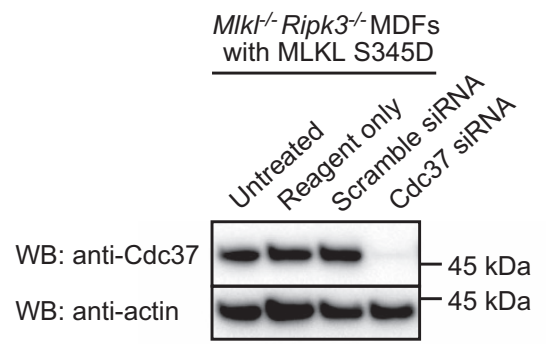

b

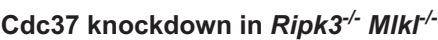 MDFs with S345D MLKL}

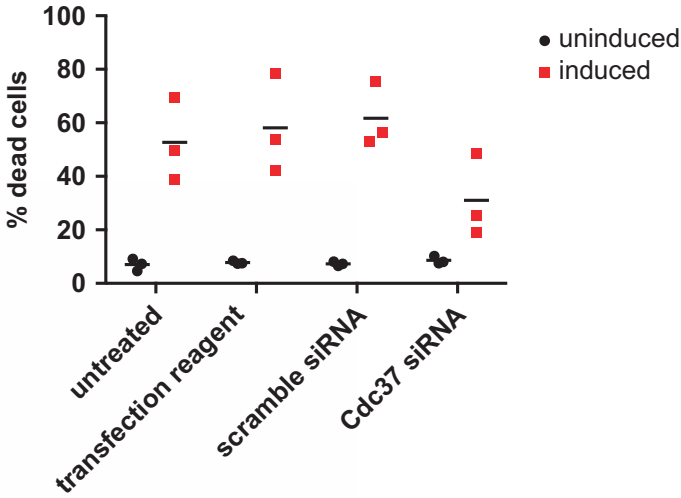

C
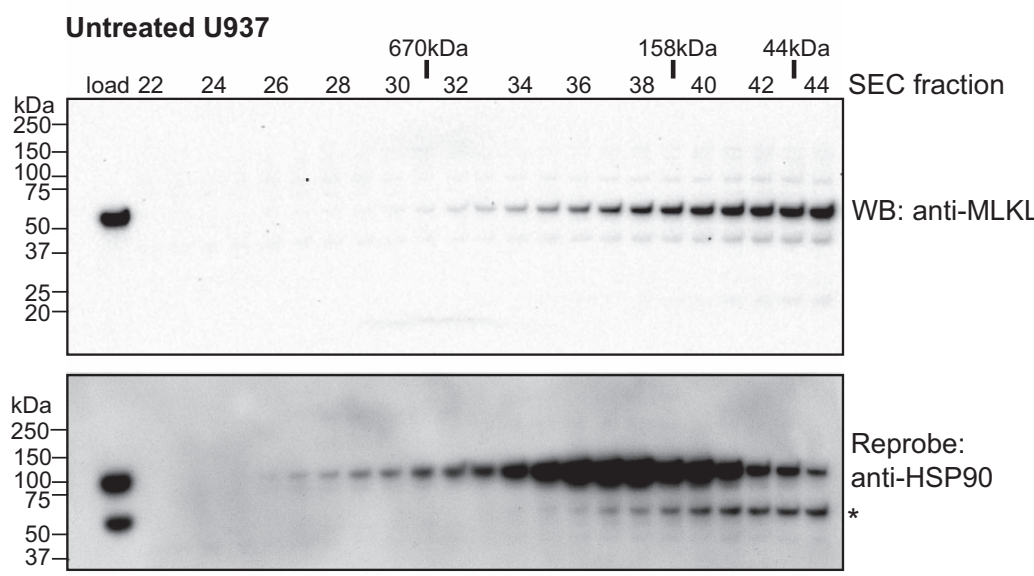

d

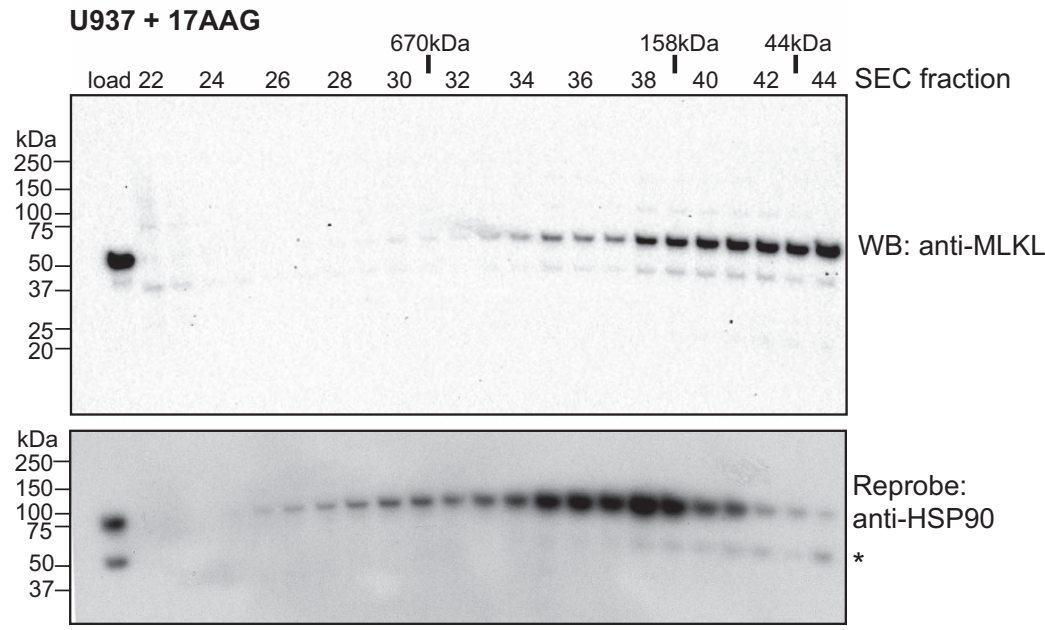

Figure 5 MLKL transiently interacts with HSP90 via the Cdc37 co-chaperone. (a and $\mathbf{b}) \mathrm{Mlk}^{\prime-}$ Ripk3-1- MDFs stably transduced with a lentiviral construct encoding S345D MLKL were untreated, treated with transfection reagent only, or transfected with scrambled or Cdc37 siRNA pools. Cdc37 knockdown was observed in Cdc37 siRNAtreated cells relative to untreated, transfection reagent and scrambled siRNA-treated controls by western blot (a). Only Cdc37 siRNA knockdown conferred protection from S345D MLKL-mediated death (b). (c and d) Lysates of U937 cells incubated with DMSO (c) or 17-AAG (500 nM, d) were resolved by Superose-6 10/300 size-exclusion chromatography (SEC). Fractions were subjected to SDS-PAGE and western blotted for MLKL (upper panels) before reprobing for HSP90 (lower; * corresponds to residual signal from MLKL blots). The SEC fraction number is shown above the blots along with the elution position of molecular weight standards 
visualised with Immobilon Western Chemiluminescent HRP Substrate (EMD Millipore) using film or a ChemiDoc (Bio-Rad, Hercules, CA, USA).

Fractionation and Blue Native PAGE. Cells were seeded into six-well plates at $2.5 \times 10^{5}$ cells/well and allowed to settle overnight. Ripk3 ${ }^{-1-} \mathrm{Mlk}^{1-}$ MDFs stably transduced with mutant MLKL S345D were pre-incubated for $1 \mathrm{~h}$ with 17-AAG, NVP-BEP800 or DMSO as described above, then induced with $50 \mathrm{ng} / \mathrm{ml}$ doxycycline for $7 \mathrm{~h}$. In parallel, Mlk ${ }^{\prime-}$ MDFs reconstituted with full-length MLKL were induced with doxycycline, and after $3 \mathrm{~h}$ treated with TNF, Smac mimetic and QVD-OPh as described above, or left untreated for a further $5 \mathrm{~h}$. Blue Native PAGE experiments were performed on U937 cells as described previously ${ }^{51}$ following pre-treatment of cells with DMSO, 17-AAG, AT13387 or NVPBEP800 for $12 \mathrm{~h}$ and stimulation with TSQ for a further $12 \mathrm{~h}$ before lysis. Fractionation of cells into cytoplasmic and membrane fractions was performed as previously. ${ }^{28,51}$ In brief, cells were permeabilised in buffer containing $0.025 \%$ digitonin (BIOSYNTH, Staad, Switzerland), $2 \mu \mathrm{M} \mathrm{N}$-ethyl maleimide, phosphatase and protease inhibitors. Permeabilised cells were centrifuged to separate crude membrane and cytosolic fractions, which were then respectively prepared in buffers to a final concentration of $1 \% \mathrm{w} / \mathrm{v}$ digitonin. Samples were separated on a $4-16 \%$ Bis-Tris Native PAGE gel, and transferred onto PVDF for western blot analyses.

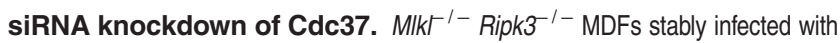
inducible MLKL S345D were seeded into 24-well plates in antibiotic-free DMEM at $2 \times 10^{4} \mathrm{cell} / \mathrm{s} /$ well in the presence of either $1 \mu \mathrm{l} / \mathrm{ml}$ DharmaFECT 1 transfection reagent (Dharmacon, Lafayette, CO, USA) and $40 \mathrm{nM}$ of pooled siRNA, consisting of four murine Cdc37 targeted oligonucleotides (cat. L-060637, Dharmacon) or scrambled non-targeting siRNA (cat. D-001810-10, Dharmacon), transfection reagent alone, or left untreated. After $24 \mathrm{~h}$, medium was changed to prevent transfection reagent toxicity. After a further $24 \mathrm{~h}, \mathrm{MLKL}$ S345D expression was induced with $50 \mathrm{ng} / \mathrm{ml}$ doxycycline or cells were left untreated. For cell death assays, cells were harvested $24 \mathrm{~h}$ after doxycycline induction $(72 \mathrm{~h}$ after original siRNA treatment) and percentage cell death assessed by propidium iodide uptake using flow cytometry. In parallel, duplicate wells were harvested using an SDS lysis buffer, and western blot was performed to verify knockdown of Cdc37 as described above.

Sizing column fractionation of U937 cell lysates. In all, $30 \times 10^{6}$ U937 cells were incubated for $18 \mathrm{~h}$ with DMSO or 17-AAG (500 nM) before lysis in $0.5 \mathrm{ml}$ ice-cold modified DISC buffer (20 mM Tris- $\mathrm{HCl}$ pH 7.4, $150 \mathrm{mM} \mathrm{NaCl}, 10 \%$ glycerol, $0.5 \%$ Triton X-100) supplemented with Complete protease inhibitor cocktail (Roche, Basel, Switzerland). Lysate was clarified by centrifugation and the supernatant injected onto a Superose-6 10/300GL size-exclusion chromatography column pre-equilibrated with lysis buffer containing Complete protease inhibitor cocktail. Protein was eluted at a flow rate of $0.4 \mathrm{ml} / \mathrm{min}$ and $0.4 \mathrm{ml}$ fractions collected. Samples were resolved by reducing SDS-PAGE on 4-12\% Bis-Tris gels (Life Technologies, Carlsbad, CA, USA), before transfer onto PVDF for western blot analyses.

\section{Conflict of Interest}

JS is a member of the Scientific Advisory Board of TetraLogic Pharmaceuticals. GL and JMM lead a programme funded by Catalyst Therapeutics Pty Ltd and the Walter and Eliza Hall Institute to develop necroptosis inhibitors.

Acknowledgements. We thank $\mathrm{Dr}$ Vishva Dixit for kindly providing Ripk3 ${ }^{-1-}$ mice, Dr Toru Okamoto for developing the inducible expression vector, Drs Marie-Liesse Asselin-Labat and Chris Burns for providing AT13387, and Mr Sam Young for assistance in generating expression constructs. This work was supported by National Health and Medical Research Council of Australia (NHMRC) grants $(1067289,1016647,1057888,1057905,1046010$ and 1016701) and fellowships to MFvD (516795), JMH (541951), DCSH (1043149) and JS (541901, 1058190); a Victorian International Research Scholarship to MCT; with additional support from the Australian Cancer Research Foundation, the Victorian State Government Operational Infrastructure Support Scheme and an NHMRC IRIISS grant (9000220). This research was facilitated by Compounds Australia; a joint initiative of Griffith University and the Queensland Government through the Smart State Innovation Fund administered by the Department of Tourism, Regional Development and Industry.
1. Silke J, Rickard JA, Gerlic M. The diverse role of RIP kinases in necroptosis and inflammation. Nat Immunol 2015; 16: 689-697.

2. Cho YS, Challa S, Moquin D, Genga R, Ray TD, Guildford M et al. Phosphorylation-driven assembly of the RIP1-RIP3 complex regulates programmed necrosis and virus-induced inflammation. Cell 2009; 137: 1112-1123.

3. Upton JW, Kaiser WJ, Mocarski ES. Virus inhibition of RIP3-dependent necrosis. Cell Host Microbe 2010; 7: 302-313.

4. Fan H, Liu F, Dong G, Ren D, Xu Y, Dou J et al. Activation-induced necroptosis contributes to B-cell lymphopenia in active systemic lupus erythematosus. Cell Death Dis 2014; 5: e1416.

5. Gunther C, Martini E, Wittkopf N, Amann K, Weigmann B, Neumann H et al. Caspase-8 regulates TNF-alpha-induced epithelial necroptosis and terminal ileitis. Nature 2011; 477: 335-339.

6. Ofengeim D, Ito Y, Najafov A, Zhang Y, Shan B, DeWitt JP et al. Activation of necroptosis in multiple sclerosis. Cell Rep 2015; 10: 1836-1849.

7. Pierdomenico M, Negroni A, Stronati L, Vitali R, Prete E, Bertin J et al. Necroptosis is active in children with inflammatory bowel disease and contributes to heighten intestinal inflammation. Am J Gastroenterol 2014; 109: 279-287.

8. Re DB, Le Verche V, Yu C, Amoroso MW, Politi KA, Phani S et al. Necroptosis drives motor neuron death in models of both sporadic and familial ALS. Neuron 2014; 81: 1001-1008.

9. Colbert LE, Fisher SB, Hardy CW, Hall WA, Saka B, Shelton JW et al. Pronecrotic mixed lineage kinase domain-like protein expression is a prognostic biomarker in patients with early-stage resected pancreatic adenocarcinoma. Cancer 2013; 119: 3148-3155.

10. He L, Peng K, Liu Y, Xiong J, Zhu FF. Low expression of mixed lineage kinase domain-like protein is associated with poor prognosis in ovarian cancer patients. Onco Targets Ther 2013; 6: 1539-1543.

11. Chromik J, Safferthal C, Serve H, Fulda S. Smac mimetic primes apoptosis-resistant acute myeloid leukaemia cells for cytarabine-induced cell death by triggering necroptosis. Cancer Lett 2014; 344: 101-109.

12. McCabe KE, Bacos K, Lu D, Delaney JR, Axelrod J, Potter MD et al. Triggering necroptosis in cisplatin and IAP antagonist-resistant ovarian carcinoma. Cell Death Dis 2014; 5: e1496.

13. Dillon CP, Weinlich R, Rodriguez DA, Cripps JG, Quarato G, Gurung P et al. RIPK1 blocks early postnatal lethality mediated by caspase-8 and RIPK3. Cell 2014; 157: 1189-1202.

14. Kaiser WJ, Daley-Bauer LP, Thapa RJ, Mandal P, Berger SB, Huang C et al. RIP1 suppresses innate immune necrotic as well as apoptotic cell death during mammalian parturition. Proc Natl Acad Sci USA 2014; 111: 7753-7758.

15. Kearney CJ, Cullen SP, Tynan GA, Henry CM, Clancy D, Lavelle EC et al. Necroptosis suppresses inflammation via termination of TNF- or LPS-induced cytokine and chemokine production. Cell Death Differ 2015; 22: 1313-1327.

16. Rickard JA, Anderton H, Etemadi N, Nachbur U, Darding M, Peltzer N et al. TNFR1dependent cell death drives inflammation in Sharpin-deficient mice. Elife 2014; 3: e03464.

17. Rickard JA, O'Donnell JA, Evans JM, Lalaoui N, Poh AR, Rogers T et al. RIPK1 regulates RIPK3-MLKL-driven systemic inflammation and emergency hematopoiesis. Cell 2014; 157: 1175-1188.

18. He S, Liang $Y$, Shao F, Wang $X$. Toll-like receptors activate programmed necrosis in macrophages through a receptor-interacting kinase-3-mediated pathway. Proc Natl Acad Sci USA 2011; 108: 20054-20059.

19. Holler N, Zaru R, Micheau O, Thome M, Attinger A, Valitutti S et al. Fas triggers an alternative, caspase-8-independent cell death pathway using the kinase RIP as effector molecule. Nat Immunol 2000; 1: 489-495.

20. Lin Y, Choksi S, Shen HM, Yang QF, Hur GM, Kim YS et al. Tumor necrosis factor-induced nonapoptotic cell death requires receptor-interacting protein-mediated cellular reactive oxygen species accumulation. J Biol Chem 2004; 279: 10822-10828.

21. Kaiser WJ, Sridharan H, Huang C, Mandal P, Upton JW, Gough PJ et al. Toll-like receptor 3mediated necrosis via TRIF, RIP3, and MLKL. J Biol Chem 2013; 288: 31268-31279.

22. Upton JW, Kaiser WJ, Mocarski ES. DAI/ZBP1/DLM-1 complexes with RIP3 to mediate virus-induced programmed necrosis that is targeted by murine cytomegalovirus vIRA. Cell Host Microbe 2012; 11: 290-297.

23. Sun L, Wang H, Wang Z, He S, Chen S, Liao D et al. Mixed lineage kinase domain-like protein mediates necrosis signaling downstream of RIP3 kinase. Cell 2012; 148: 213-227.

24. Zhao J, Jitkaew S, Cai Z, Choksi S, Li Q, Luo J et al. Mixed lineage kinase domain-like is a key receptor interacting protein 3 downstream component of TNF-induced necrosis. Proc Natl Acad Sci USA 2012; 109: 5322-5327.

25. Murphy JM, Czabotar PE, Hildebrand JM, Lucet IS, Zhang JG, Alvarez-Diaz S et al. The pseudokinase MLKL mediates necroptosis via a molecular switch mechanism. Immunity 2013; 39: 443-453.

26. Murphy JM, Lucet IS, Hildebrand JM, Tanzer MC, Young SN, Sharma P et al. Insights into the evolution of divergent nucleotide-binding mechanisms among pseudokinases revealed by crystal structures of human and mouse MLKL. Biochem J 2014; 457: 369-377.

27. Czabotar PE, Murphy JM. A tale of two domains - a structural perspective of the pseudokinase, MLKL. FEBS J 2015; 282: 4268-4278.

28. Hildebrand JM, Tanzer MC, Lucet IS, Young SN, Spall SK, Sharma P et al. Activation of the pseudokinase MLKL unleashes the four-helix bundle domain to induce membrane localization and necroptotic cell death. Proc Natl Acad Sci USA 2014; 111: 15072-15077.

29. Chen X, Li W, Ren J, Huang D, He WT, Song Y et al. Translocation of mixed lineage kinase domain-like protein to plasma membrane leads to necrotic cell death. Cell Res 2014; 24: 105-121. 
30. Wang H, Sun L, Su L, Rizo J, Liu L, Wang LF et al. Mixed lineage kinase domain-like protein MLKL causes necrotic membrane disruption upon phosphorylation by RIP3. Mol Cell 2014; 54: 133-146.

31. Taipale M, Krykbaeva I, Koeva M, Kayatekin C, Westover KD, Karras Gl et al. Quantitative analysis of HSP90-client interactions reveals principles of substrate recognition. Cell 2012 150: 987-1001.

32. Chen G, Cao P, Goeddel DV. TNF-induced recruitment and activation of the IKK complex require Cdc37 and Hsp90. Mol Cell 2002; 9: 401-410.

33. Lyu J, Wesselschmidt RL, Lu W. Cdc37 regulates Ryk signaling by stabilizing the cleaved Ryk intracellular domain. J Biol Chem 2009; 284: 12940-12948.

34. Terasawa K, Shinozaki F, Minami M, Minami Y. Client binding of Cdc37 is regulated intramolecularly and intermolecularly. Biosci Biotechnol Biochem 2006; 70: 1542-1546.

35. Xu W, Mollapour M, Prodromou C, Wang S, Scroggins BT, Palchick Z et al. Dynamic tyrosine phosphorylation modulates cycling of the HSP90-P50(CDC37)-AHA1 chaperone machine. Mol Cell 2012; 47: 434-443.

36. Chen WW, Yu H, Fan HB, Zhang CC, Zhang M, Zhang C et al. RIP1 mediates the protection of geldanamycin on neuronal injury induced by oxygen-glucose deprivation combined with zVAD in primary cortical neurons. J Neurochem 2012; 120: 70-77.

37. Fearns C, Pan Q, Mathison JC, Chuang TH. Triad3A regulates ubiquitination and proteasomal degradation of RIP1 following disruption of Hsp90 binding. J Biol Chem 2006; 281: 34592-34600.

38. Gentle IE, Wong WW, Evans JM, Bankovacki A, Cook WD, Khan NR et al. In TNF-stimulated cells, RIPK1 promotes cell survival by stabilizing TRAF2 and cIAP1, which limits induction of non-canonical NF-kappaB and activation of caspase-8. J Biol Chem 2011; 286: 13282-13291.

39. Lewis J, Devin A, Miller A, Lin Y, Rodriguez Y, Neckers L et al. Disruption of hsp90 function results in degradation of the death domain kinase, receptor-interacting protein (RIP), and blockage of tumor necrosis factor-induced nuclear factor-kappaB activation. J Biol Chem 2000; 275: 10519-10526.

40. Pantano C, Shrivastava P, McElhinney B, Janssen-Heininger Y. Hydrogen peroxide signaling through tumor necrosis factor receptor 1 leads to selective activation of c-Jun N-terminal kinase. J Biol Chem 2003; 278: 44091-44096.

41. Vanden Berghe T, Kalai M, van Loo G, Declercq W, Vandenabeele P. Disruption of HSP90 function reverts tumor necrosis factor-induced necrosis to apoptosis. J Biol Chem 2003; 278 $5622-5629$

42. Li D, Xu T, Cao Y, Wang H, Li L, Chen S et al. A cytosolic heat shock protein 90 and cochaperone CDC37 complex is required for RIP3 activation during necroptosis. Proc Nat Acad Sci USA 2015; 112: 5017-5022.

43. Park SY, Shim JH, Cho YS. Distinctive roles of receptor-interacting protein kinases 1 and 3 in caspase-independent cell death of L929. Cell Biochem Funct 2014; 32: 62-69.

44. Brough PA, Barril X, Borgognoni J, Chene P, Davies NG, Davis B et al. Combining hit identification strategies: fragment-based and in silico approaches to orally active 2-aminothieno[2,3-d]pyrimidine inhibitors of the Hsp90 molecular chaperone. J Med Chem 2009; 52: 4794-4809.

45. Schulte TW, Neckers LM. The benzoquinone ansamycin 17-allylamino-17demethoxygeldanamycin binds to HSP90 and shares important biologic activities with geldanamycin. Cancer Chemother Pharmacol 1998; 42: 273-279.

46. Woodhead AJ, Angove H, Carr MG, Chessari G, Congreve M, Coyle JE et al. Discovery of (2,4-dihydroxy-5-isopropylphenyl)-[5-(4-methylpiperazin-1-ylmethyl)-1,3-dihydrois oindol-2yl]methanone (AT13387), a novel inhibitor of the molecular chaperone Hsp90 by fragment based drug design. J Med Chem 2010; 53: 5956-5969.

47. Khattar V, Fried J, Xu B, Thottassery JV. Cks1 proteasomal degradation is induced by inhibiting Hsp90-mediated chaperoning in cancer cells. Cancer Chemother Pharmacol 2015 75: 411-420.

48. Boczek EE, Reefschlager LG, Dehling M, Struller TJ, Hausler E, Seidl et al. Conformational processing of oncogenic v-Src kinase by the molecular chaperone Hsp90. Proc Natl Acad Sci USA 2015; 112: E3189-E3198.

49. Lachowiec J, Lemus T, Thomas JH, Murphy PJ, Nemhauser JL, Queitsch C. The protein chaperone HSP90 can facilitate the divergence of gene duplicates. Genetics 2013; 193 : 1269-1277.

50. Lu XA, Wang X, Zhuo W, Jia L, Jiang $Y$, Fu $Y$ et al. The regulatory mechanism of a client kinase controlling its own release from Hsp90 chaperone machinery through phosphorylation. Biochem J 2014; 457: 171-183.

51. Tanzer MC, Tripaydonis A, Webb Al, Young SN, Varghese LN, Hall C et al. Necroptosis signalling is tuned by phosphorylation of MLKL residues outside the pseudokinase domain activation loop. Biochem J 2015; 471: 255-265.

52. Cook WD, Moujalled DM, Ralph TJ, Lock P, Young SN, Murphy JM et al. RIPK1- and RIPK3induced cell death mode is determined by target availability. Cell Death Differ 2014; 21: $1600-1612$.

53. Tanzer MC, Matti I, Hildebrand JM, Young SN, Wardak A, Tripaydonis A et al. Evolutionary divergence of the necroptosis effector MLKL. Cell Death Differ (in press).
54. Allonby O, El Zawily AM, Freywald T, Mousseau DD, Chlan J, Anderson D et al. Ligand stimulation induces clathrin- and Rab5-dependent downregulation of the kinase-dead EphB6 receptor preceded by the disruption of EphB6-Hsp90 interaction. Cell Signal 2014; 26: 2645-2657.

55. Aoyagi Y, Fujita N, Tsuruo T. Stabilization of integrin-linked kinase by binding to Hsp90. Biochem Biophys Res Commun 2005; 331: 1061-1068.

56. Radovanac K, Morgner J, Schulz JN, Blumbach K, Patterson C, Geiger T et al. Stabilization of integrin-linked kinase by the Hsp90-CHIP axis impacts cellular force generation, migration and the fibrotic response. EMBO J 2013; 32: 1409-1424.

57. Gerbin CS, Landgraf R. Geldanamycin selectively targets the nascent form of ERBB3 for degradation. Cell Stress Chaperones 2010; 15: 529-544.

58. Theodoraki MA, Caplan AJ. Quality control and fate determination of $\mathrm{Hsp} 90$ client proteins. Biochim Biophys Acta 2012; 1823: 683-688.

59. Hinz M, Broemer M, Arslan SC, Otto A, Mueller EC, Dettmer R et al. Signal responsiveness of IkappaB kinases is determined by Cdc37-assisted transient interaction with Hsp90. J Biol Chem 2007; 282: 32311-32319.

60. Cai Z, Jitkaew S, Zhao J, Chiang HC, Choksi S, Liu J et al. Plasma membrane translocation of trimerized MLKL protein is required for TNF-induced necroptosis. Nat Cell Biol 2014; 16 : $55-65$.

61. Dondelinger Y, Declercq W, Montessuit S, Roelandt R, Goncalves A, Bruggeman I et al. MLKL compromises plasma membrane integrity by binding to phosphatidylinositol phosphates. Cell Rep 2014; 7: 971-981.

62. Li R, Soosairajah J, Harari D, Citri A, Price J, $\mathrm{Ng} \mathrm{HL}$ et al. Hsp90 increases LIM kinase activity by promoting its homo-dimerization. FASEB J 2006; 20: 1218-1220.

63. Erazo T, Moreno A, Ruiz-Babot G, Rodriguez-Asiain A, Morrice NA, Espadamala J et al. Canonical and kinase activity-independent mechanisms for extracellular signal-regulated kinase 5 (ERK5) nuclear translocation require dissociation of Hsp90 from the ERK5-Cdc37 complex. Mol Cell Biol 2013; 33: 1671-1686.

64. Jha KN, Coleman AR, Wong L, Salicioni AM, Howcroft E, Johnson GR. Heat shock protein 90 functions to stabilize and activate the testis-specific serine/threonine kinases, a family of kinases essential for male fertility. J Biol Chem 2013; 288: 16308-16320.

65. Wang Y, Xu W, Zhou D, Neckers L, Chen S. Coordinated regulation of serum- and glucocorticoid-inducible kinase 3 by a C-terminal hydrophobic motif and Hsp90-Cdc37 chaperone complex. J Biol Chem 2014; 289: 4815-4826.

66. Mazalouskas MD, Godoy-Ruiz R, Weber DJ, Zimmer DB, Honkanen RE, Wadzinski BE. Small G proteins Rac1 and Ras regulate serine/threonine protein phosphatase 5 (PP5). extracellular signal-regulated kinase (ERK) complexes involved in the feedback regulation of Raf1. J Biol Chem 2014; 289: 4219-4232.

67. Takai $\mathrm{H}$, Xie $\mathrm{Y}$, de Lange $\mathrm{T}$, Pavletich NP. Tel2 structure and function in the Hsp90-dependent maturation of mTOR and ATR complexes. Genes Dev 2010; 24: 2019-2030.

68. Adwan TS, Ohm AM, Jones DN, Humphries MJ, Reyland ME. Regulated binding of importinalpha to protein kinase Cdelta in response to apoptotic signals facilitates nuclear import. J Biol Chem 2011; 286: 35716-35724.

69. Park SY, Shim JH, Chae JI, Cho YS. Heat shock protein 90 inhibitor regulates necroptotic cell death via down-regulation of receptor interacting proteins. Pharmazie 2015; 70: 193-198.

70. Sidera K, Patsavoudi E. HSP90 inhibitors: current development and potential in cancer therapy. Recent Pat Anticancer Drug Discov 2014; 9: 1-20.

71. Vince JE, Wong WW, Khan N, Feltham R, Chau D, Ahmed AU et al. IAP antagonists target CIAP1 to induce TNFalpha-dependent apoptosis. Cell 2007; 131: 682-693.

72. Bossen C, Ingold K, Tardivel A, Bodmer JL, Gaide O, Hertig S et al. Interactions of tumor necrosis factor (TNF) and TNF receptor family members in the mouse and human. $J$ Biol Chem 2006; 281: 13964-13971.

73. Newton K, Sun X, Dixit VM. Kinase RIP3 is dispensable for normal NF-kappa Bs, signaling by the B-cell and T-cell receptors, tumor necrosis factor receptor 1 , and Toll-like receptors 2 and 4. Mol Cell Biol 2004; 24: 1464-1469.

(i) Cell Death and Disease is an open-access journal published by Nature Publishing Group. This work is licensed under a Creative Commons Attribution 4.0 International License. The images or other third party material in this article are included in the article's Creative Commons license, unless indicated otherwise in the credit line; if the material is not included under the Creative Commons license, users will need to obtain permission from the license holder to reproduce the material. To view a copy of this license, visit http://creativecommons.org/licenses/by/4.0/ 